Research Article

\title{
Experimental Investigation of Crack Initiation and Propagation in the Unreinforced Masonry Specimen Subjected to Vertical Settlement
}

\author{
Junbo Wang $\mathbb{D},{ }^{1,2}$ Weibing $\mathrm{Hu}\left(\mathbb{D},{ }^{1}\right.$ Xinyu Wang $\mathbb{D},{ }^{2,3}$ and Yaozhe Liang $\mathbb{C}^{4}$ \\ ${ }^{1}$ School of Civil Engineering, Xi'an University of Architecture and Technology, Xi'an 710055, China \\ ${ }^{2}$ School of Civil Engineering, Henan Polytechnic University, Jiaozuo 454000, China \\ ${ }^{3}$ Henan Province Engineering Laboratory for Eco-architecture and the Built Environment, Henan Polytechnic University, \\ Jiaozuo 454000, China \\ ${ }^{4}$ Hebei Academy of Building Research Co., Ltd., Shijiazhuang 050021, China
}

Correspondence should be addressed to Xinyu Wang; wangxinyu2010@163.com and Yaozhe Liang; kcsj5257@163.com

Received 7 December 2020; Revised 24 January 2021; Accepted 1 February 2021; Published 13 February 2021

Academic Editor: Shazim A. Memon

Copyright (C) 2021 Junbo Wang et al. This is an open access article distributed under the Creative Commons Attribution License, which permits unrestricted use, distribution, and reproduction in any medium, provided the original work is properly cited.

\begin{abstract}
To study the cracking process of the wall caused by differential settlement under a uniformly distributed load on the top of the wall, a laboratory model experiment was carried out on large-scale masonry specimens, and the acoustic emission (AE) technique and digital close-range industrial photogrammetry were adopted to monitor the AE signals and displacement characteristics of the masonry specimens during loading in real time. The results show that, in the case of differential settlement with small settlement on both sides and large settlement in the middle, two main cracks appear on the left and right sides of the wall, extending obliquely from bottom to top. During the loading process, damage of the wall is aggravated due to the differential settlement, and both cumulative ringing count and energy count have different periods of steep rise. With the increase in the load and activation of the $\mathrm{AE}$ event, the $\mathrm{AE}$ event becomes active, and the cumulative ringing count and cumulative energy curve have an obvious turning point, where the slope of the curve is substantially higher than that before the turning point. By using digital close-range industrial photogrammetry, it is observed that the main oblique crack on the left is mainly caused by the difference in the vertical deformation, while the main oblique crack on the right is caused by different displacements and deformation directions of the wall on both sides of the crack.
\end{abstract}

\section{Introduction}

Masonry is widely used worldwide due to its availability, ease of construction, and low cost. However, masonry structures also have the disadvantages of poor bearing capacity, poor earthquake resistance, and easy cracking. Among them, wall cracking is common in all kinds of masonry buildings. The causes of wall cracking include stress on the upper structure, change in external temperature, and differential settlement of the foundation, in addition to the characteristics of the material itself (mortar shrinkage, brick expansion, brickmortar bonding performance, etc.). Among them, cracking of the masonry wall caused by differential settlement of the foundation is the most common cause of cracking. The accumulation of differential settlement not only leads to cracking but also excessive deformation or even collapse of the masonry structure. Even if there is no structural damage to the masonry structures, the existence of cracks will affect their normal use. Therefore, it is necessary to conduct an in-depth study on wall cracking caused by differential settlement.

The causes of differential foundation settlement can be divided into three categories: (1) the load distribution on the upper part of the building is uneven, resulting in uneven additional stress on the foundation soil of the bearing stratum; (2) the uneven distribution of the thickness of the bearing stratum or soft underlayer results in the uneven compression deformation of soil; and (3) the excavation of tunnels or deep foundation pits leads to lateral movement of 
adjacent soil, thus causing differential settlement of the foundation soil of adjacent buildings. In recent years, cracking or even damage of masonry structures caused by differential settlement has gained more attention. The main methods to study the crack initiation and propagation in masonry structures subjected to vertical settlement include theoretical analysis [1, 2], numerical simulation [3-7], and laboratory test. Numerical tools have been favorably preferred over the analytical method, given the complex mechanical response and the irregular geometries of the masonry structure. Also, the reliability of both theoretical methods and numerical models needs to be verified by experiments. However, there are not too many studies on settlement tests of the masonry structures, especially the large-scale model at present [8-12]. Due to the limitation of the scale and structure-soil interaction, Giardina et al. [13-15] used scaled models to test the damage and crack propagation of the masonry structures due to tunnel excavation. Portioli and Cascini $[16,17]$ applied a set of experimental tests to study the mechanical performance of a masonry structure under the action of foundation settlement. Torres et al. [18] used a full-scale model to conduct the laboratory model experiment to study how differential settlement of the bottom influences a masonry cross vault. Verstrynge et al. [2, 19] took advantage of the good mechanical properties of polyurethane and filled the area between the supporting points at the bottom of the wall with polyurethane panels to simulate compressible soil and obtained desired results. However, the experimental load in the papers is to apply concentrated load on the top of the wall, and the situation that the wall bears uniform load in actual engineering is more common.

In large-scale model experiments, it is essential to effectively monitor wall damage and crack propagation. Acoustic emission (AE), as a dynamic nondestructive monitoring technique, is not only easy to install and operate but also capable of continuous monitoring and data collection. With these advantages, this technique has been widely used in structural state assessment, damage locating, and damage evolution detection [20-29].

This paper aims to study the cracking problem of unreinforced masonry caused by differential vertical deformation subjected to a uniform load. The unreinforced masonry wall is supported on two concrete blocks, and the area between the support points is filled with polyurethane plates to simulate the existence of a compressible soil. During the experiment, AE technology and digital closerange industrial photogrammetry system were used to monitor the brick wall, and the AE signal characteristics and digital photogrammetry results were used to achieve the purpose of accurate real-time monitoring of the inside damage evolution, surface damage location, and crack propagation of the masonry structure.

\section{Experiment Model}

Experiments were conducted to study the cracking of the wall due to differential settlement of the wall bottom under uniform loading. By using acoustic emission and digital photography technology, the damage, deformation, and crack propagation of the wall during loading were monitored.

2.1. Materials and Samples. Photos and three-view drawings of the brick masonry specimen are shown in Figures 1 and 2 . The specimen was built with solid clay bricks and cement mortar by header bond. Its size includes the dimensions of length $\times$ height $\times$ thickness $=2070 \mathrm{~mm} \times 1502$ $\mathrm{mm} \times 240 \mathrm{~mm}$, with a total of 24 layers. The size of each brick is $h \times b \times t=240 \mathrm{~mm} \times 115 \mathrm{~mm} \times 53 \mathrm{~mm}$. These bricks were recycled from a dismantled masonry structure that has been used for nearly 20 years.

The mortar used is $10 \mathrm{~mm}$-thick cement mortar, and the proportions of the masonry mortar mixtures are shown in Table 1. Among them, the cement is 32.5 general Portland cement, and the sand is fine river sand with a mud content of less than 5\%. According to the requirements of the Test Methods for Wall Bricks (GB/T2542-2012) [30], 10 singlebrick samples are made, and average compressive strength of the bricks is $9.85 \mathrm{MPa}$. The average compressive strength of the masonry mortar measured with cube test blocks of $70.7 \mathrm{~mm} \times 70.7 \mathrm{~mm} \times 70.7 \mathrm{~mm}$ [31] is $10.22 \mathrm{MPa}$.

The wall was supported by two concrete blocks, and the area between the two blocks was filled with polyurethane panels to support the specimen and simulate the compressible soil $[2,19]$. Through fitting the compression test of five polyurethane cubes with dimensions of $100 \mathrm{~mm} \times 100 \mathrm{~mm} \times 100 \mathrm{~mm}$ test cubes, the elastic modulus was $29.8 \mathrm{~N} / \mathrm{mm}^{2}$. Once completed, the masonry specimen was pressed flat on its top for at least 14 days to ensure a good bond between the brick and the mortar. Before the test, the specimen was cured for 28 days in the laboratory at a temperature of $20 \pm 5^{\circ} \mathrm{C}$ and a relative humidity of $65 \% \pm 5 \%$ [32].

2.2. Test Equipment and Parameters. In the test, the load was applied by a hydraulic in situ pressure testing machine, and the maximum uniaxial load was $5000 \mathrm{kN}$. The AE test system, which was from Beijing Softland Times Scientific and Technology Co., Ltd., consisted of a holographic AE data acquisition instrument and DS2A system analysis software, as shown in Figure 3(a). The AE sampling frequency was $3 \mathrm{MHz}$, and the data were stored in the form of waveform. The sensor (RS150M) had a wide frequency range of $60-400 \mathrm{kHz}$, a resonance frequency of $150 \mathrm{kHz}$, a sensitivity peak of $75 \mathrm{~dB}$, and a preamplifier gain of $40 \mathrm{~dB}$. The $\mathrm{AE}$ system is shown in Figure 3(a). The AE time parameter$s$-peak definition time (PDT), hit definition time (HDT), and hit lock time (HLT)-were set to $50 \mu \mathrm{s}, 100 \mu \mathrm{s}$, and $200 \mu$ s, respectively [27, 28].

The digital photogrammetry system used is Xi'an Jiaotong University Digital Close-range Industrial Photogrammetry System (XJTUDP), as shown in Figure 3(b). The system can accurately obtain the three-dimensional coordinates of discrete target points. It is a portable and mobile three-coordinate optical measurement system that can be used for quality control of static work pieces, dynamic deformation analysis, and real-time measurement. 


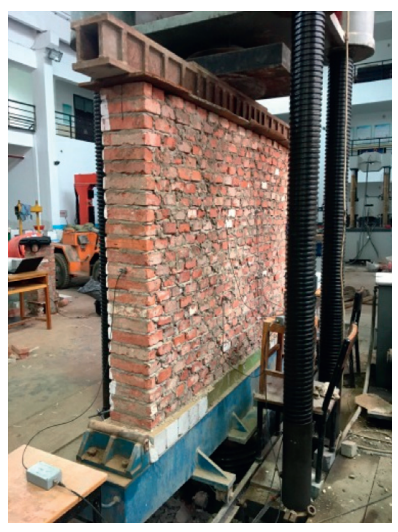

(a)

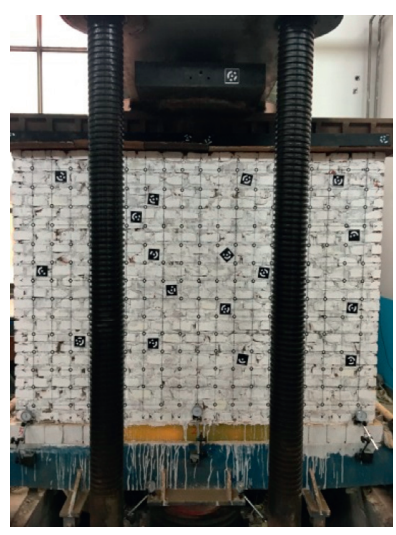

(b)

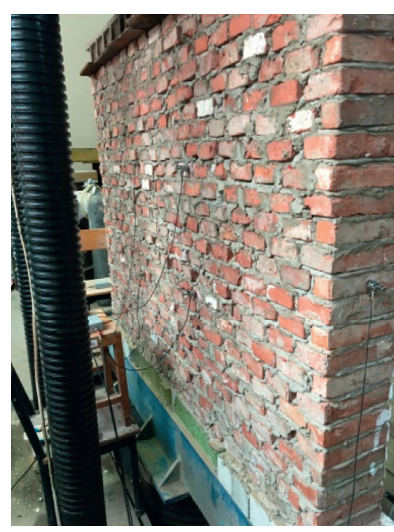

(c)

Figure 1: The scene photograph.

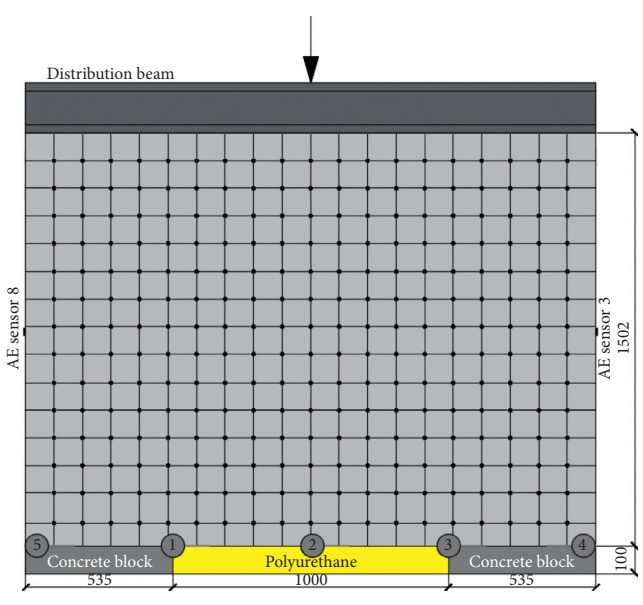

Electronic digital micrometer

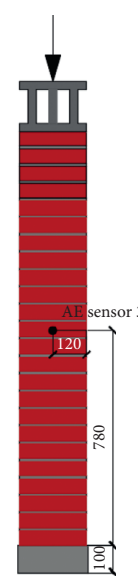

(b)

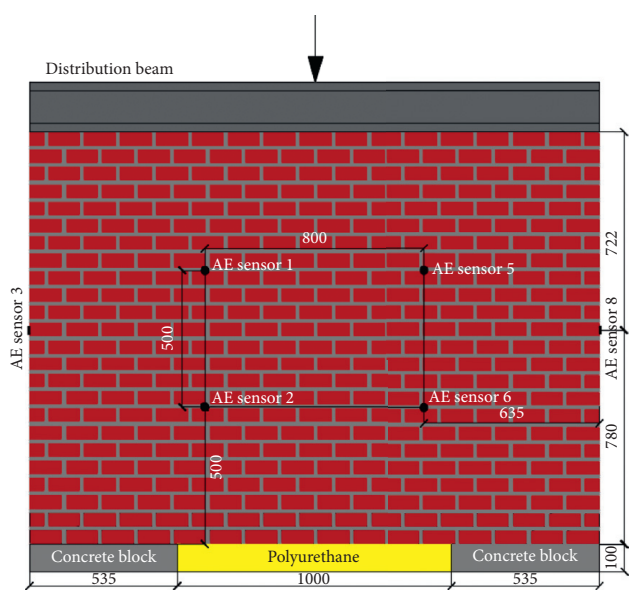

(c)

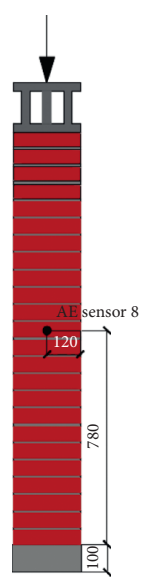

(d)

Figure 2: The three-view drawing of the brick wall (unit: mm). (a) Front view. (b) Right view. (c) Back view. (d) Left view.

TABle 1: Proportions of mortar mixtures $\left(\mathrm{kg} / \mathrm{m}^{3}\right)$.

\begin{tabular}{lcc}
\hline Cement & Sand & Water \\
\hline 290 & 1550 & 270 \\
\hline
\end{tabular}

2.3. Specimen Loading and Measurement Scheme. A vertical load was applied on the top of the specimen, and the vertical compressive stress was distributed uniformly on the top of the wall through the steel beam. Before the test, $10 \%$ of the estimated failure load should be preloaded 3 times. The relative error of the axial deformation value on the two wide sides should not exceed $10 \%$. If this percentage is exceeded, the test specimen should be repositioned or relevelled. After preloading, the load should be removed, and the initial data should be recorded. After that, loading shall be started gradually. The load increment was $50 \mathrm{kN}$, and the loading rate was $0.75 \mathrm{kN} / \mathrm{s}$. After $2 \mathrm{~min}$ of constant loading, the next stage of load was applied. The test specimen shall not be impacted when the load is applied. The loading curve is shown in Figure 4 . The loading equipment and monitoring points are shown in Figure 2. Four AE sensors were installed on the back elevation of the test specimen; one AE sensor was installed at the centre of the left and right side elevations; and five electronic micrometers were placed at five positions-two ends of the wall bottom and two ends and middle of the polyurethane panels - to monitor the change in the settlement at different positions under the wall. After the front elevation of the wall was whitened with putty, grid lines with a spacing of $10 \mathrm{~cm}$ were drawn, and noncoding points were installed at the intersections of the lines. At the same time, noncoding points were installed as evenly as possible in other positions of the wall, as shown in Figure 1, to monitor the deformation of each point on the wall at different loading levels.

\section{Results and Discussion}

3.1. Failure Characteristics. Figure 5 shows the crack propagation and distribution at the front elevation of the wall during loading. In the figure, $\mathrm{C}$ represents the cracks, the numbers represent the sequence of cracks, and the cracks at different stages are represented by different colors. At the initial loading stage, the whole wall deformation was 


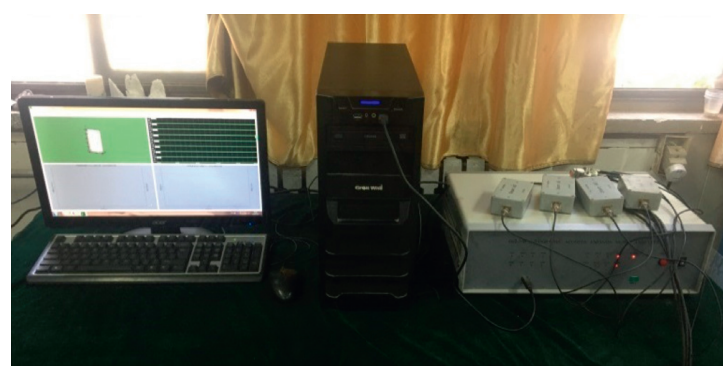

(a)

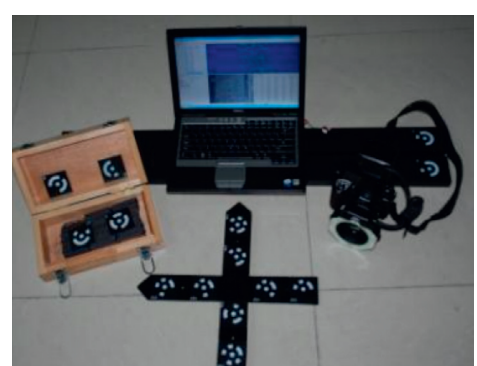

(b)

FIgURE 3: Experimental equipment. (a) AE data acquisition system. (b) Hardware composition of XJTUDP.

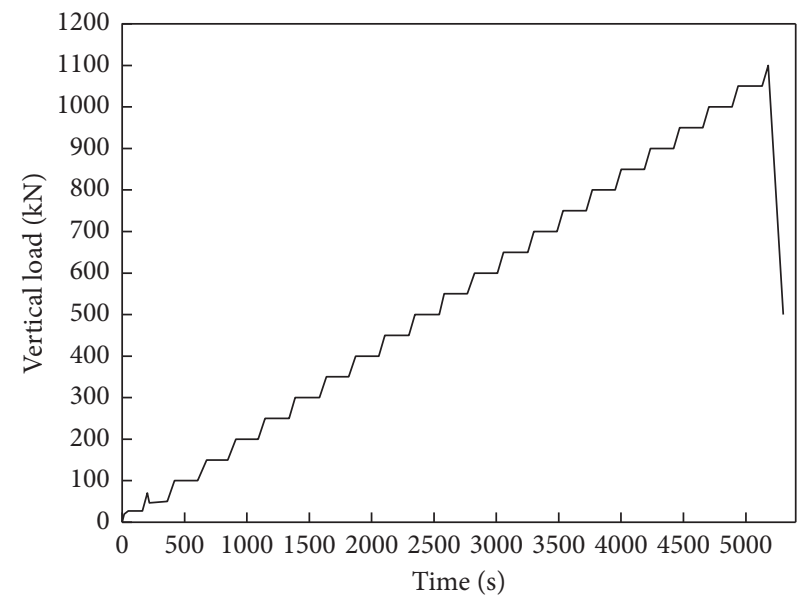

(a)

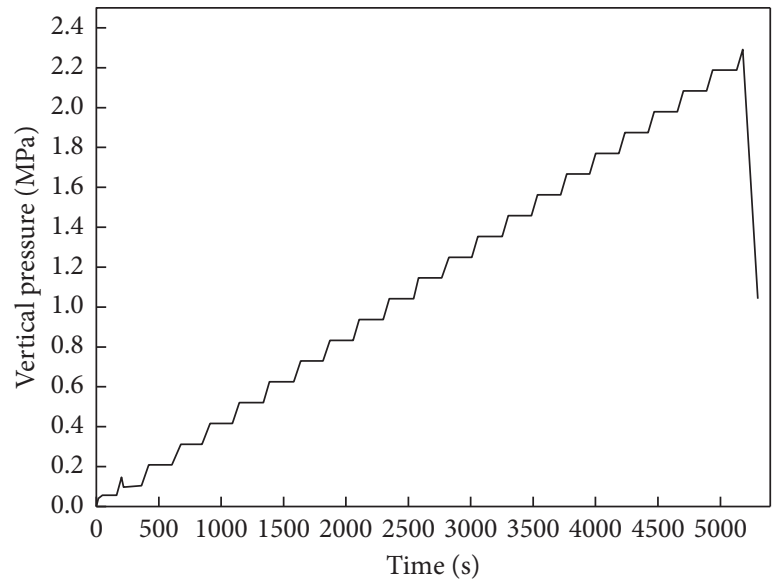

(b)

Figure 4: The loading curve. (a) The loading curve of the testing machine. (b) Converted to wall top pressure.

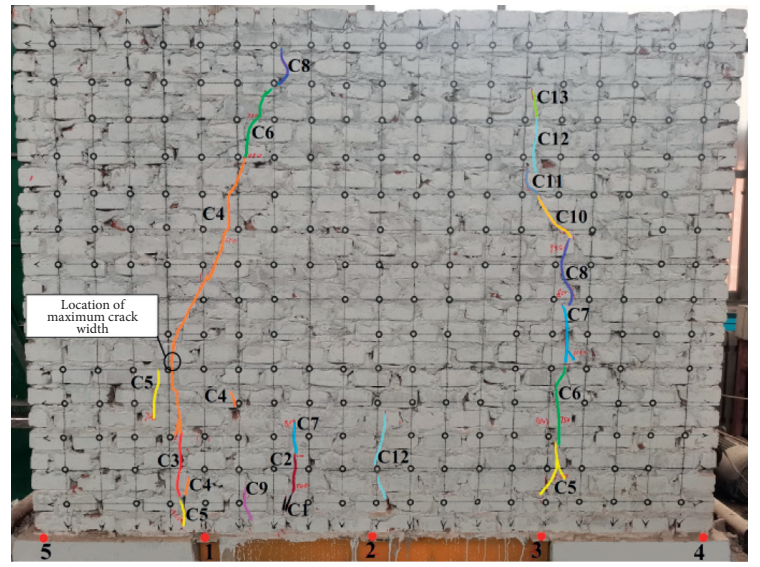

Figure 5: Distribution of wall cracks.

uniform when the load on the wall was small, and when the load increased to $1.04 \mathrm{MPa}$, the first visible crack appeared on the wall (see crack C1 in Figure 5). It developed from the left-centre position at the bottom of the wall. As the load continued to increase, crack $\mathrm{C} 1$ further expanded to crack C2; when the load increased to 1.25 $\mathrm{MPa}$, crack C3 appeared on the left side of the wall (the upper part between the concrete and the polyurethane panel); during the loading process from $1.25 \mathrm{MPa}$ to $1.35 \mathrm{MPa}$, crack C3 rapidly expanded to C4; when the load increased to $1.46 \mathrm{MPa}, \mathrm{C} 5$ appeared on the right side (the upper part between the concrete and the polyurethane panel) and the left side of the wall, respectively; when the applied load reached $1.56 \mathrm{MPa}$, the cracks on both sides expanded upwards to C6; when the load increased to $1.77 \mathrm{MPa}$, the cracks on the right side of the wall expanded upwards from $\mathrm{C} 6$ to $\mathrm{C} 8$, and the cracks on the left side of the wall (C3-C4-C5-C6-C8) were connected with each other; when the load finally increased to $2.29 \mathrm{MPa}$, the cracks on the right side of the wall (C5-C6-C7-C8-C10-C11C12-C13) were connected with each other. As a result, there were two oblique cracks on the left and right sides of the wall from bottom to top and several secondary cracks (C1-C2C7, C9, and C12) in the lower-middle part of the wall. The experimental results show that the main oblique cracks on both sides of the wall do not appear at the same time and that these cracks are not symmetrically distributed. The reason might be that there are gaps between the polyurethane panels and the concrete on the left and right sides, and these gaps are not consistent in width, leading to the appearance of differential settlement of the two sides at different times.

Figure 6 shows the vertical deformation of the monitoring points at the bottom of the wall under different pressures on the top of the wall. The two ends (points 4 and 5) of the wall bottom are supported by concrete. These two points have a relatively large compression-induced 


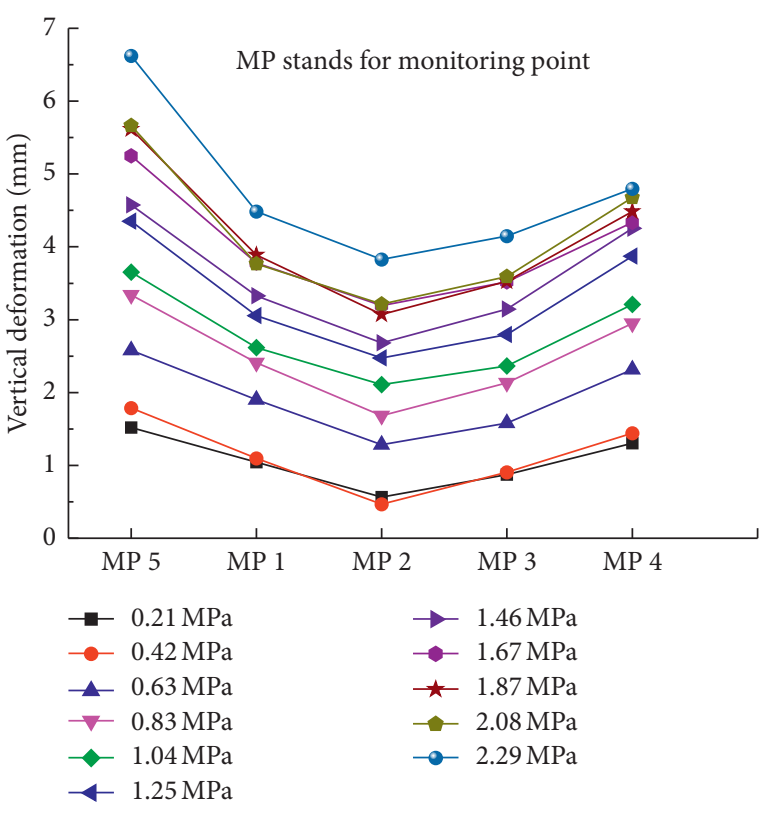

FIgURE 6: The settlement curve of monitoring points.

deformation, and the final deformation is $4.8 \mathrm{~mm}$ and $6.62 \mathrm{~mm}$, respectively. Point 2 is in the middle of the wall bottom, and settlement-induced deformation at this point occurs from the beginning of loading. When the vertical pressure on the wall is $1.04 \mathrm{MPa}$, the difference between the vertical deformation of point 2 and point 5 is $1.55 \mathrm{~mm}$, and the first visible crack appears on the wall; when the vertical pressure is $1.77 \mathrm{MPa}$, the difference is $2.54 \mathrm{~mm}$, and the left oblique crack is connected from bottom to top; when the vertical pressure is $2.29 \mathrm{MPa}$, the difference reaches $2.8 \mathrm{~mm}$, and the right oblique crack gets connected from bottom to top. At this point, the loading stops, and two main oblique cracks form on both sides of the wall.

Figure 7 shows the curve of the maximum crack width monitored during loading. Before the crack propagates to $\mathrm{C} 4$, the maximum crack width is at the bottom of $\mathrm{C} 1$. After the crack propagates to $\mathrm{C} 4$, the maximum crack width appears in the lower middle of the left main oblique crack (as shown in Figure 5). In this case, the maximum crack width is $0.22 \mathrm{~mm}$ when the load is $1.35 \mathrm{MPa}, 1.2 \mathrm{~mm}$ when the load is $1.77 \mathrm{MPa}$, and $1.7 \mathrm{~mm}$ when the load is $2.29 \mathrm{MPa}$, as shown in Figure 7. Due to the good mechanical properties of the polyurethane panel, such as compressive resilience, the maximum compression- and settlement-induced deformation of point 2 is restored to $0.154 \mathrm{~mm}$ from $1.845 \mathrm{~mm}$ after the load is removed, and the maximum crack width on the wall is restored to $0.6 \mathrm{~mm}$. To some extent, this indicates that, in the case of masonry wall cracking due to differential settlement, reinforcing the foundation (such as by grouting reinforcement) can reduce the crack width of the wall to effectively control crack propagation.

\subsection{AE Signal Characteristic Analysis}

3.2.1. Ringing Count Characteristic Analysis. The ringing count refers to the number of oscillations of the voltage signal beyond the threshold. It is a characteristic parameter

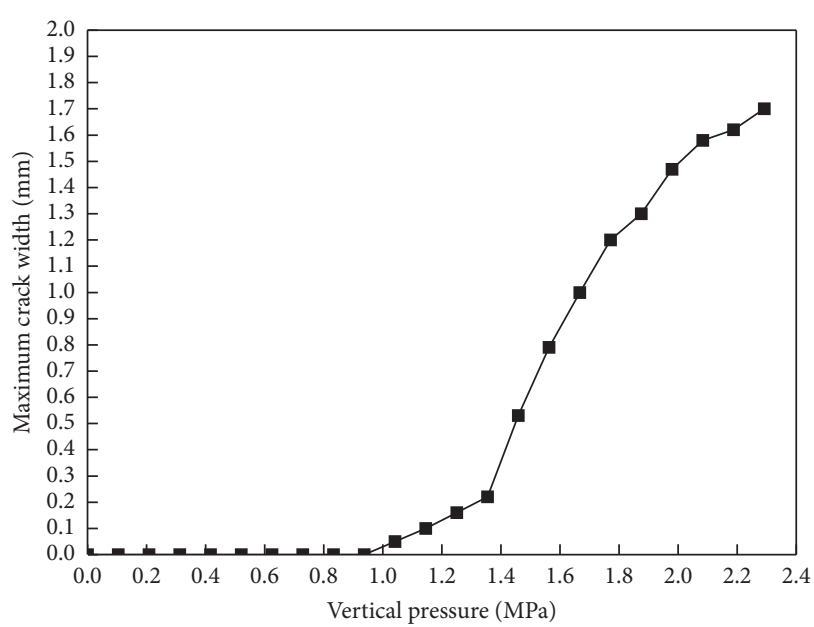

Figure 7: The maximum crack width curve.

commonly used in AE monitoring and evaluation. By extracting the data of $\mathrm{AE}$ sensors from each channel of the wall specimen, the relationship between the ringing count, the cumulative ringing count, and the load and time was obtained, as shown in Figure 8. Figure 8(a) shows the relationship curve of the ringing count, cumulative ringing count, and load over time obtained for $\mathrm{AE}$ sensor 5 . According to this curve, the $\mathrm{AE}$ ringing count does not appear in the first $465 \mathrm{~s}$. This is mainly because of the Kaiser effect. Specifically, AE events will not occur before the upper load reaches the initial preload value $(0.208 \mathrm{MPa})$; when the upper load exceeds the preload value (after $465 \mathrm{~s}$ ), a small amount of AE signals starts to appear on the wall. These signals are mainly caused by the compaction of bricks and mortar with initial defects, microvoids, and microcracks. As the loading continues, the ringing count remains relatively stable at a lower level, and as the load grows, stress is redistributed inside the masonry specimen, and the microcracks generated in the mortar and brick begin to extend both upwards and downwards. At approximately $2460 \mathrm{~s}$ (the upper pressure is $1.04 \mathrm{MPa}$ ), AE events are activated, and the ringing count increases substantially. After $2940 \mathrm{~s}$ (the upper pressure is $1.25 \mathrm{MPa}$ ), the ringing count grows sharply and then enters a flat period after $2960 \mathrm{~s}$. At $4570 \mathrm{~s}$ (the upper pressure is $1.89 \mathrm{MPa}$ ), the ringing count increases obviously and then enters a flat period after $4620 \mathrm{~s}$, from $5201 \mathrm{~s}$ until the end of the experiment (the upper pressure is $2.29 \mathrm{MPa}$ ), there is a third steep rise in the ringing count, and the final cumulative ringing count is $705.34 \times 10^{3}$. AE sensors 1 and 2 have similar trends in the relationship curve of ringing count, cumulative ringing count, and load over time (Figures $8(\mathrm{c})$ and $8(\mathrm{~d})$ ) but fewer cumulative ringing times $\left(162.64 \times 10^{3}\right.$ and $136.69 \times 10^{3}$, respectively), and their last steep rise is shorter. For AE sensors 6, 3, and 8, their curves (Figures 8(b), 8(e), and 8(f), respectively) only exhibit two steep rises at $2940 \mathrm{~s}-2960 \mathrm{~s}$ and $5201 \mathrm{~s}$ to the end of the experiment, and their cumulative ringing counts are $323.76 \times 10^{3}, 323.4 \times 10^{3}$, and $344.89 \times 10^{3}$, respectively. The results show that the most cumulative ringing counts are detected near AE sensor 5, indicating that the damage is more severe near this position. Compared with the two $\mathrm{AE}$ 


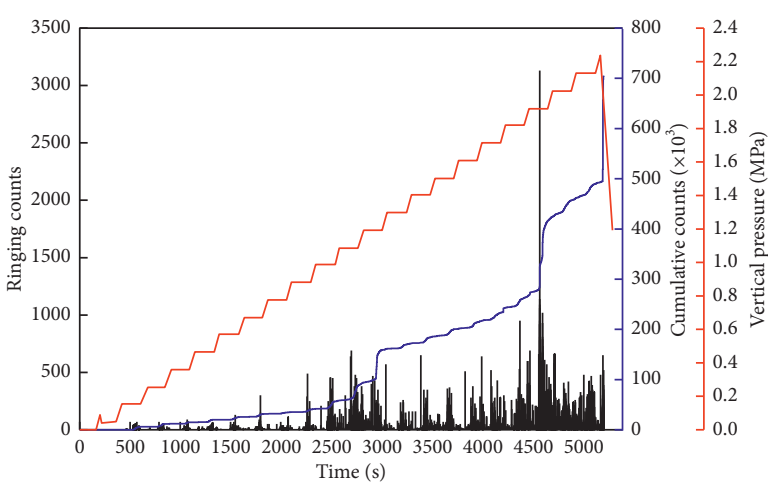

(a)

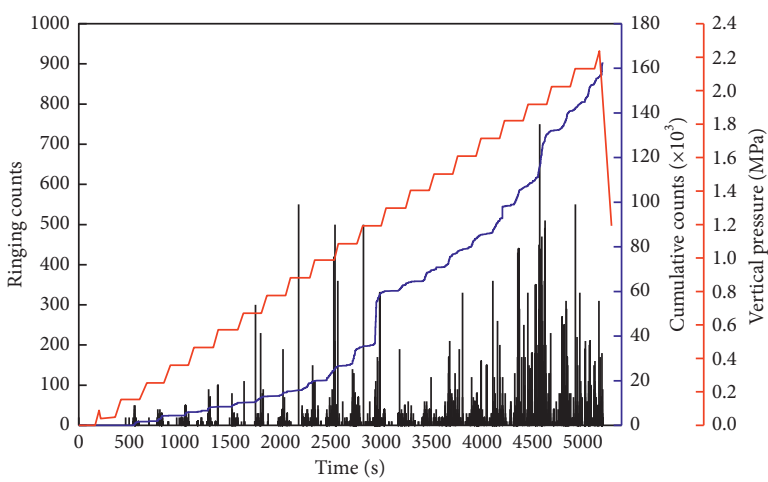

(c)

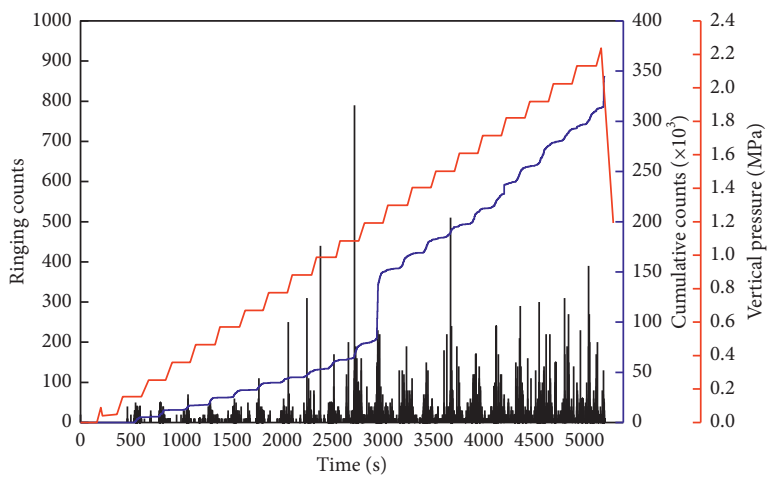

(e)

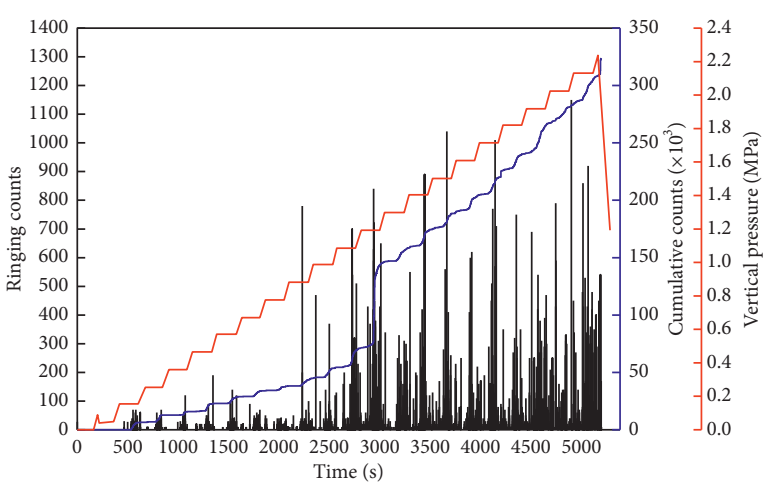

(b)

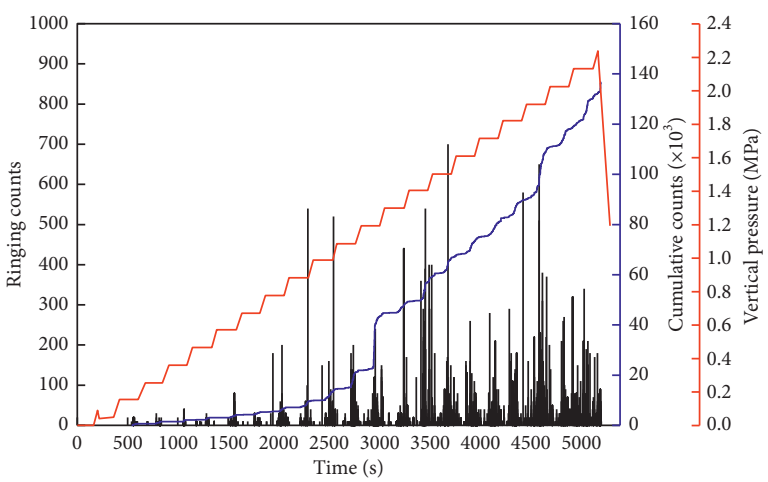

(d)

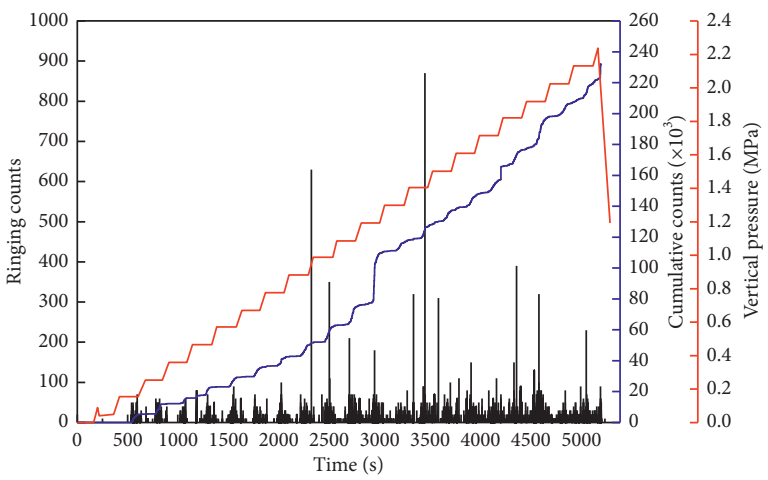

(f)

FIGURE 8: Variation of AE ringing counts and load with time for AE sensors. (a) AE sensor 5. (b) AE sensor 6. (c) AE sensor 1. (d) AE sensor 2. (e) AE sensor 8. (f) AE sensor 3.

sensors at the lower wall, the two $\mathrm{AE}$ sensors at the upper wall detect more cumulative ringing counts, indicating that damage of the upper wall is more severe than that of the lower wall. The cumulative ringing count monitored at the left elevation is substantially higher than that at the right elevation.

In the initial stage of loading, the $\mathrm{AE}$ ringing count is relatively low and stable, and the curve of the cumulative ringing count shows a slow linear increase. As the load increases and the $\mathrm{AE}$ events are activated, the curve of the cumulative ringing count has an obvious turning point, and the slope of the curve is substantially higher than that in the early stage of loading. In the later stage of loading, due to frequent $\mathrm{AE}$ activities, the ringing count is relatively high, and the curve slope of the cumulative ringing count reaches its maximum.

During the experiment, due to the difference in the distance between the sound source and the sensors, the difference in the propagation distance of the stress wave, and the difference in the distribution of the brick and mortar, the ringing count received by each sensor is different, but the curves of the cumulative ringing count follow roughly the same trend.

3.2.2. Energy Characteristic Analysis. AE energy refers to the area under the detection envelope of the AE signal, which can reflect the relative intensity of the $\mathrm{AE}$ event. The 
variations in the $\mathrm{AE}$ energy, cumulative energy, and load with time for AE sensors are shown in Figure 9. In the initial stage of loading, as no $\mathrm{AE}$ event occurs, the $\mathrm{AE}$ energy of the masonry specimen is blank. When the load exceeds the preload value, an occasional high level of AE energy occurs, but the overall trend is stable, and the cumulative AE energy increases linearly with the load. At approximately $2460 \mathrm{~s}$ (the upper pressure is $1.04 \mathrm{MPa}$ ), $\mathrm{AE}$ events are activated, and the energy release capacity is greatly increased. At $2720 \mathrm{~s}$ (the upper pressure is $1.14 \mathrm{MPa}$ ), the cumulative energy increases sharply with the first obvious rise and then enters a flat period at $2780 \mathrm{~s}$. At $2950 \mathrm{~s}$ (the upper pressure is $1.25 \mathrm{MPa}$ ), the cumulative energy exhibits another steep rise and then enters a flat period at $2980 \mathrm{~s}$. After $4530 \mathrm{~s}$ (the upper pressure is $1.87 \mathrm{MPa}$ ), the cumulative energy exhibits a third steep rise and then enters a flat period at $4630 \mathrm{~s}$, and from $5201 \mathrm{~s}$ until the end of the experiment (the upper pressure is $2.29 \mathrm{MPa}$ ), the fourth sharp increase occurs. Finally, the cumulative energy values for $\mathrm{AE}$ sensors $5,6,8,1,2$, and 3 are $654.53 \times 10^{3} \mathrm{mV} \cdot \mathrm{mS}, \quad 510.68 \times 10^{3} \mathrm{mV} \cdot \mathrm{mS}, \quad 360.76 \times$ $10^{3} \mathrm{mV} \cdot \mathrm{mS}, 447.02 \times 10^{3} \mathrm{mV} \bullet \mathrm{mS}, 224.91 \times 10^{3} \mathrm{mV} \bullet \mathrm{mS}$, and $208.1 \times 10^{3} \mathrm{mV} \bullet \mathrm{mS}$, respectively.

With the continuous release of the AE energy, the energy level of the masonry specimen increases substantially. When the pressure on the top of the wall reaches $1.04 \mathrm{MPa}$, the $\mathrm{AE}$ events become active, and the cumulative energy curve shows an obvious turning point. In the later stage of loading, the cumulative energy curve continues to increase linearly, but the slope of the curve is substantially higher than that before the turning point. Moreover, the energy levels of the AE sensors arranged on the front elevation of the specimen are higher than those on the side elevations.

\subsubsection{Amplitude-Energy Relationship Analysis. Figure 10} shows the scatter diagrams of the amplitude and energy. Among the AE parameters, the amplitude and energy are both important parameters of AE signals. The amplitude is directly related to the size of the event and is not affected by its threshold value. The amplitude directly determines the measurability of the event, while the energy reflects the relative energy or intensity of the event.

According to the scatter diagrams, the maximum energy is obtained from AE sensor 5 at approximately $3000 \mathrm{~s}$, which is $5354.52 \mathrm{mV} \cdot \mathrm{mS}$; the maximum amplitude appears at approximately $2722 \mathrm{~s}$, with a value of $9994.51 \mathrm{mV}$. As measured by the sensors of the other channels, the maximum energy values detected by other sensors are below $4000 \mathrm{mV} \bullet \mathrm{mS}$, and the maximum amplitude values are all below $10000 \mathrm{mV}$. The variations in the amplitude and energy follow basically the same trend. A sudden increase in the amplitude value is accompanied by a substantial change in the energy value, and vice versa. The overall change in the two parameters corresponds to the wall crack propagation process and is stage-based. Specifically, in the early stage of microcrack initiation, the changes in the energy and amplitude values are relatively gentle, and their stage-based abrupt changes correspond to the damage-fracture process of the wall. As the microcracks gather to form initial cracks, the energy and amplitude values increase and change relatively evenly. When the microcracks expand to macroscopic cracks, the energy and amplitude values grow dramatically. In the event of macrocrack instability, both values are substantially reduced. It can be seen that the amplitude and energy are consistent in the variation of the signal strength, and both can directly reflect the size of an event.

\subsection{Displacement of Mark Points on the Wall.} Close-range industrial photogrammetry is a technology that converts the structural features of the measured object's surface into high-precision discrete three-dimensional (3D) coordinates based on digital image processing and photogrammetry. This process is as follows: coding and noncoding points are placed on and around the surface of the measured object, and then images are taken from different angles and positions, as shown in Figure 11. Through digital image processing and centre positioning of the points, accurate pixel coordinates of the geometric centre of the points are obtained. Based on these results, through the relative orientation, 3D reconstruction, beam adjustments, and the introduction of the scale factor of the scale bar, the accurate three-dimensional coordinates of all points can be calculated. In XJTUDP $[33,34]$, the coding points are used to orient the images and automatically calculate the position of the camera. When taking images, it is recommended to capture as many points as possible that are evenly distributed on the object to obtain a higher measurement accuracy. Generally, noncoding points instead of coding points are used to determine the three-dimensional coordinates of the measured object. They are automatically identified by XJTUDP and numbered randomly, as shown in Figure 12. Through analytical calculations of the 3D coordinates of the noncoding points on the wall, the displacement change nephogram of each point under different loads is obtained, which helps identify crack growth in the wall.

In this section, the method in [35] was used to calibrate the accuracy of the XJTUDP system, and the layout scheme for point position precision evaluation of the photogrammetry system is shown in Figure 13; the distance values of six groups composed of different coding points (46-53, 49-66, $63-76,64-78,120-121$, and 122-123) were measured by the XJTUDP system for 10 times, respectively, and the experimental data are shown in Table 2. The accuracy range of the XJTUDP system is $0.03-0.1 \mathrm{~mm}$, and the experimental accuracy range is $0.0405-0.0697 \mathrm{~mm}$, which shows that the system has a high accuracy in the measurement process.

Figure 14 shows the displacement vector nephogram of the characteristic points of the wall under various loads. Table 3 shows the vertical and horizontal deformation values of some noncoding points near the main oblique cracks on the left and right sides. It is evident that, in the early stage, as the load is small, the upper wall deforms vertically, while the lower wall deforms both vertically and horizontally, and the deformation on the left side of the wall is larger than that on the right side. As the load increases, the wall deformation increases. When the load reaches $1.04 \mathrm{MPa}$, visible cracks 


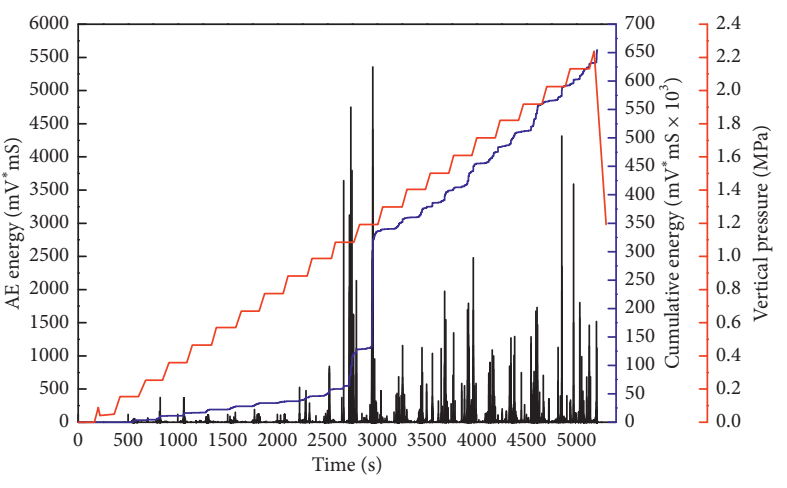

(a)

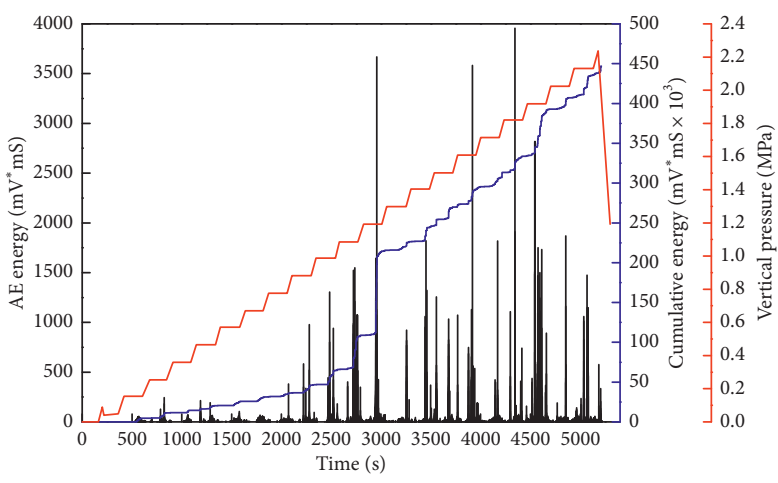

(c)

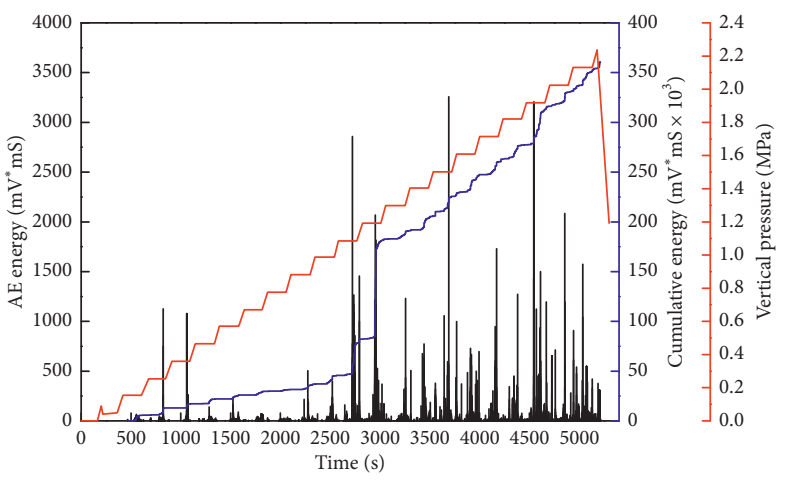

(e)

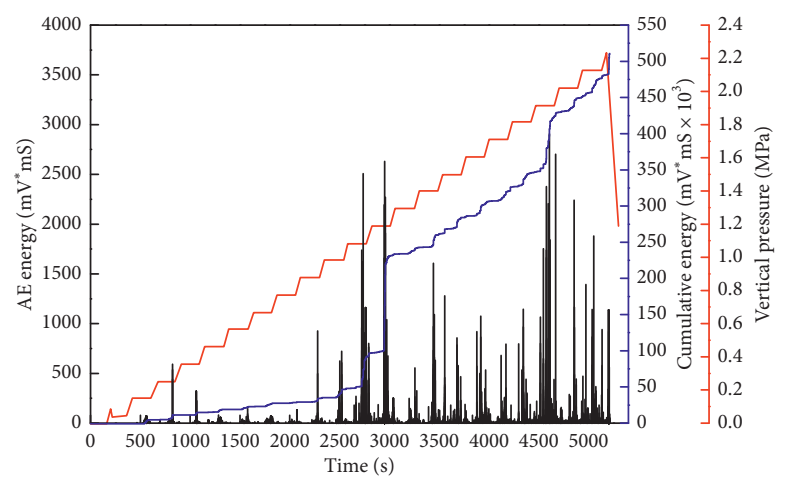

(b)

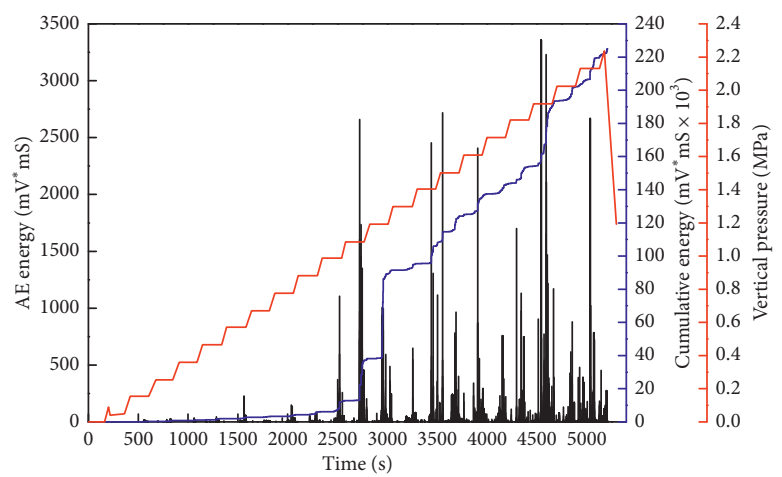

(d)

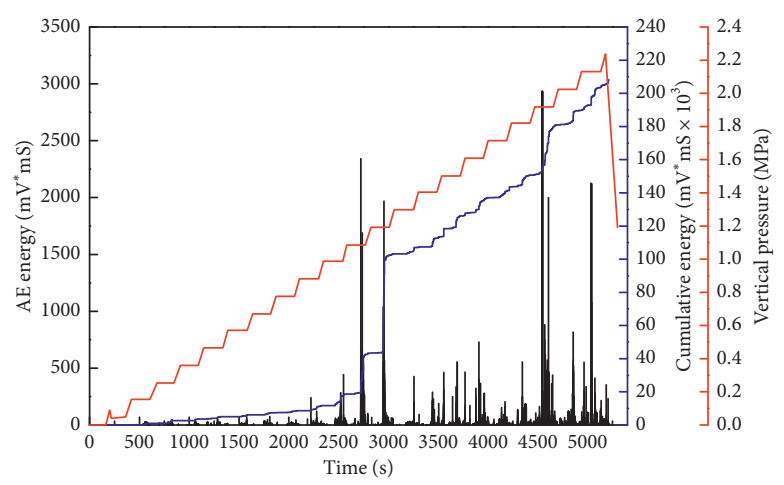

(f)

Figure 9: Variation of AE energy and load with time for AE sensors. (a) AE sensor 5. (b) AE sensor 6. (c) AE sensor 1. (d) AE sensor 2. (e) AE sensor 8. (f) AE sensor 3.

appear near the middle of the wall bottom. At this time, differential settlement of the wall appears. According to Table 3, a settlement difference of $0.28 \mathrm{~mm}$ is generated between noncoding points 1156 and 1115 on the left side of the wall. When the pressure is $1.25 \mathrm{MPa}$, the deformation differences between noncoding points 1156 and 1115 are greater than $0.5 \mathrm{~mm}$ in both vertical and horizontal directions, and the differential settlement of the whole wall is obvious. Above the "soft-hard" junction at the bottom of the left wall, visible cracks begin to develop. When the pressure rises to $1.87 \mathrm{MPa}$, the vertical and horizontal deformation differences between noncoding points 1156 and 1115 reach $1.09 \mathrm{~mm}$ and $0.80 \mathrm{~mm}$, respectively, and the left oblique crack is connected from bottom to top. When the pressure is $2.29 \mathrm{MPa}$, the vertical and horizontal deformation differences between noncoding points 1156 and 1115 reach $1.40 \mathrm{~mm}$ and $1.10 \mathrm{~mm}$, respectively. At this time, a vertical deformation difference of more than $0.5 \mathrm{~mm}$ appears between the noncoding points of each layer near the left main oblique crack, demonstrating the effect of the differential settlement. During the loading process, the vertical deformation difference between the noncoding points on both sides of the main crack on the right is approximately $0.2 \mathrm{~mm}$, while there are some differences in horizontal deformation. When the pressure is $1.45 \mathrm{MPa}$, it is found that the horizontal deformation of noncoding point 1146 increases from $-0.6548 \mathrm{~mm}$ to $-0.7391 \mathrm{~mm}$, while the horizontal deformation of point 1005 in the same 


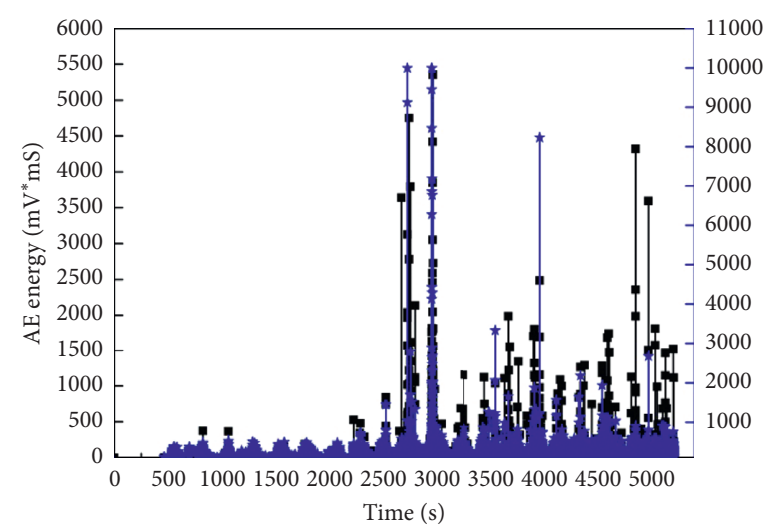

(a)

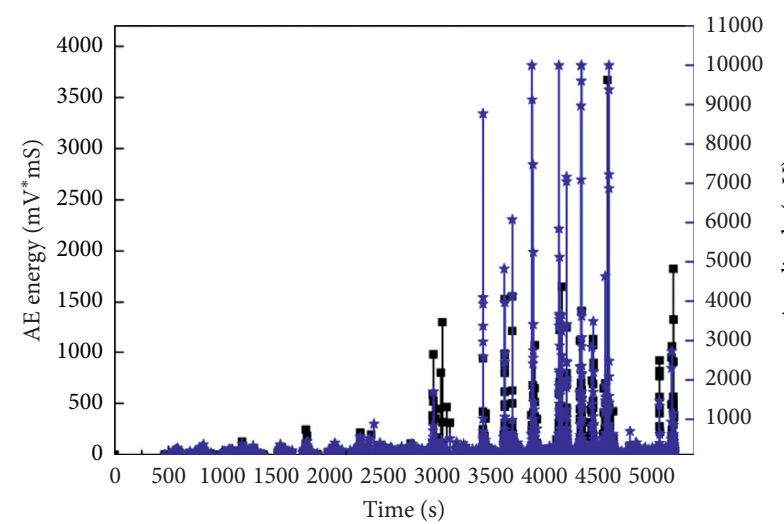

(c)

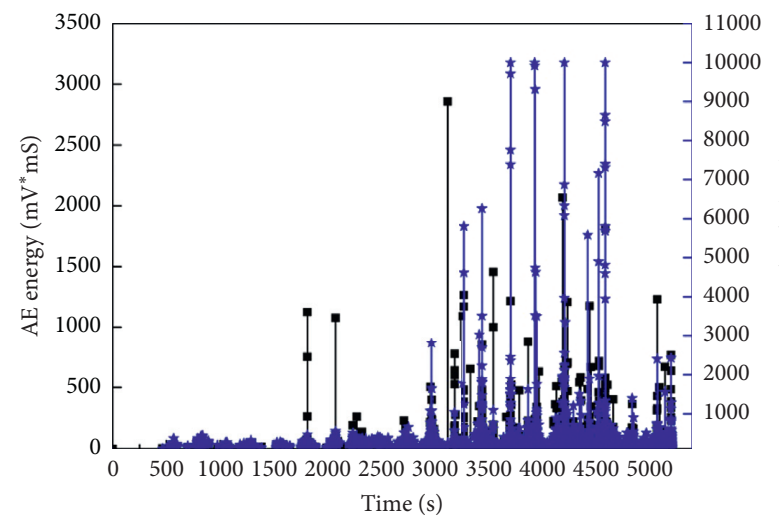

(e)

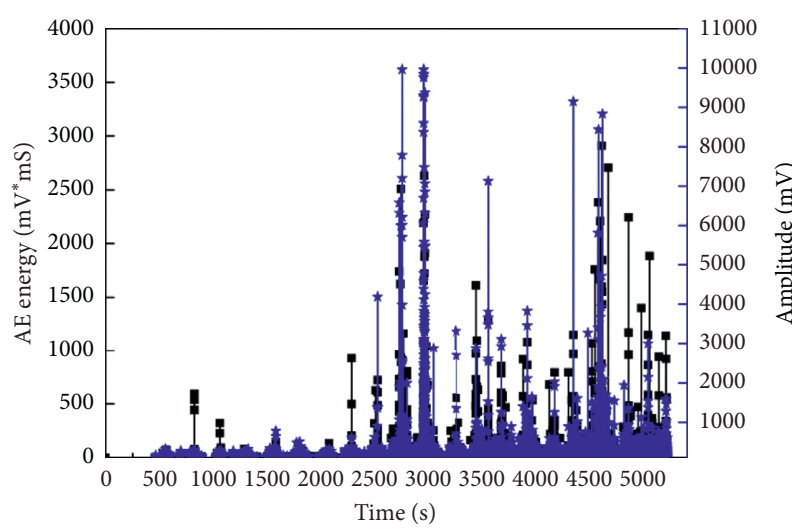

(b)

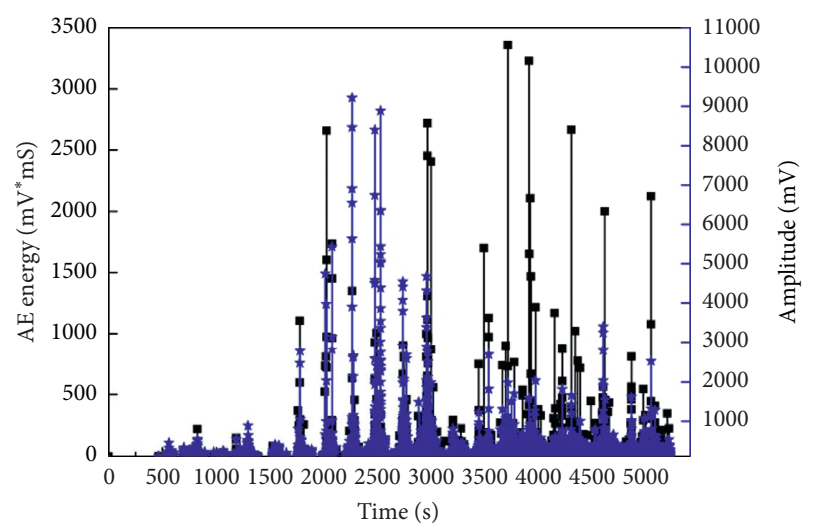

(d)

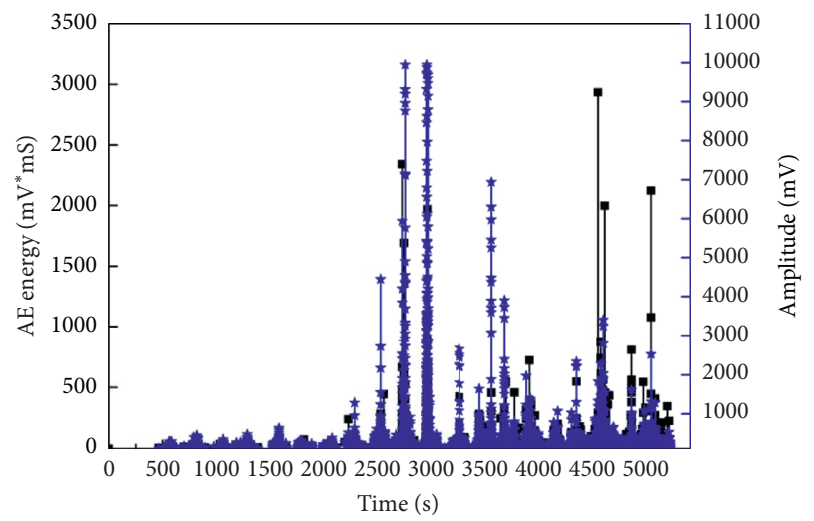

(f)

Figure 10: Amplitude energy scatter diagrams. (a) AE sensor 5. (b) AE sensor 6. (c) AE sensor 1. (d) AE sensor 2. (e) AE sensor 8. (f) AE sensor 3.

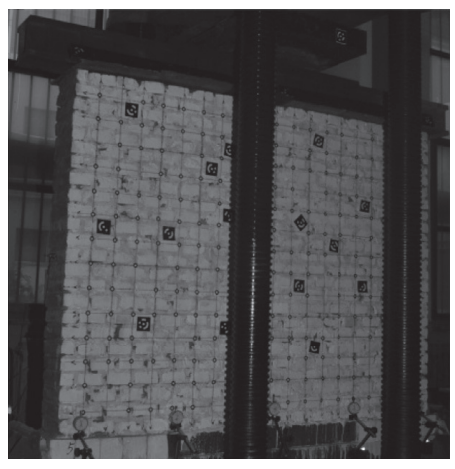

(a)

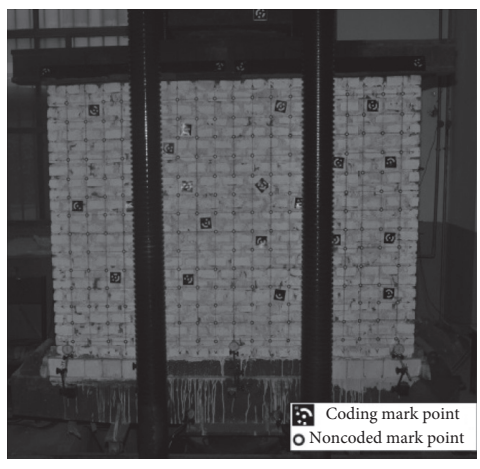

(b)

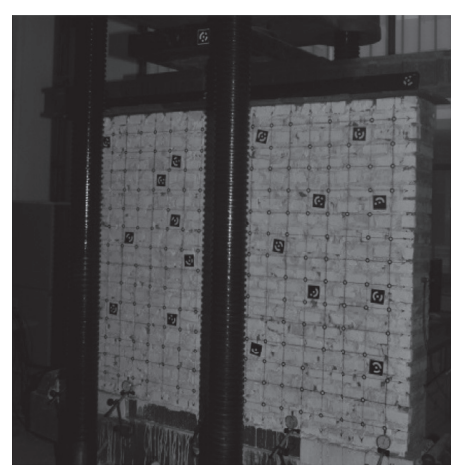

(c)

Figure 11: Experimental photos. 


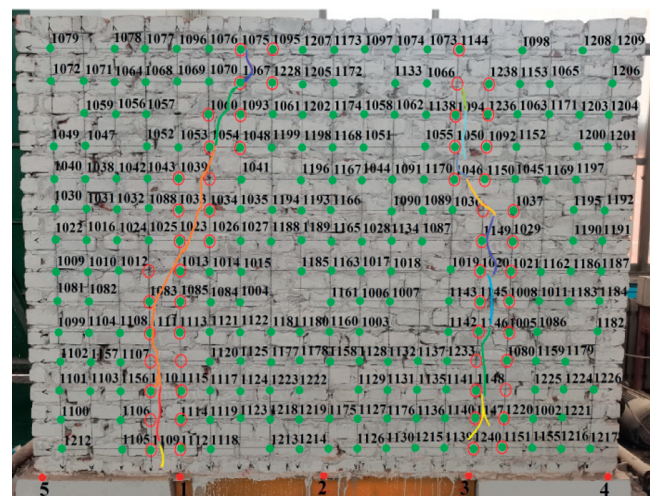

Figure 12: The identification code (ID) of the noncoding point.

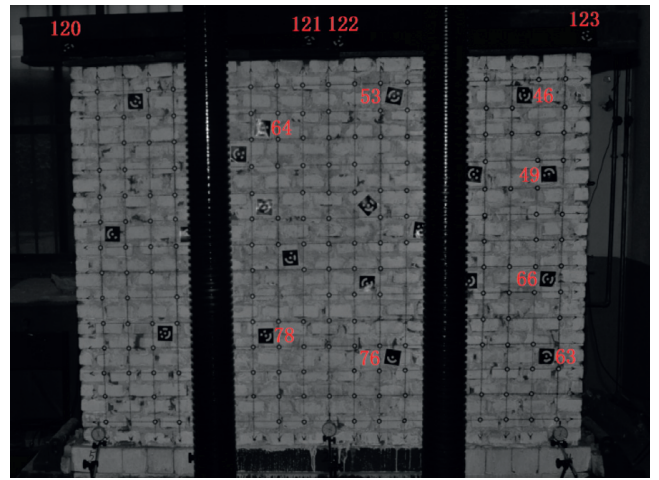

FIGURE 13: The layout scheme for point position precision evaluation of the photogrammetry system.

TABLE 2: Distance mean square error of the photogrammetry system $(\mathrm{mm})$.

\begin{tabular}{|c|c|c|c|c|c|c|}
\hline & $46-53$ & $49-66$ & $63-76$ & $64-78$ & $120-121$ & $122-123$ \\
\hline 1 & 488.723 & 400.016 & 600.108 & 801.612 & 902.239 & 899.978 \\
\hline 2 & 488.806 & 400.103 & 599.996 & 801.562 & 902.168 & 899.863 \\
\hline 3 & 488.732 & 400.018 & 600.011 & 801.652 & 902.303 & 900.033 \\
\hline 4 & 488.769 & 400.022 & 599.909 & 801.493 & 902.189 & 899.906 \\
\hline 5 & 488.741 & 400.051 & 600.002 & 801.528 & 902.224 & 900.007 \\
\hline 6 & 488.759 & 400.029 & 600.009 & 801.521 & 902.152 & 899.989 \\
\hline 7 & 488.751 & 400.032 & 599.981 & 801.499 & 902.209 & 900.017 \\
\hline 8 & 488.789 & 400.063 & 600.001 & 801.606 & 902.213 & 899.971 \\
\hline 9 & 488.871 & 400.055 & 600.012 & 801.611 & 902.271 & 900.015 \\
\hline 10 & 488.833 & 400.106 & 600.003 & 801.512 & 902.164 & 900.009 \\
\hline Mean squared error (MSE) & 0.0474 & 0.0331 & 0.0478 & 0.0567 & 0.0483 & 0.0541 \\
\hline Nominal accuracy $((\sqrt{3 / 2}) \cdot \mathrm{MSE})$ & 0.0581 & 0.0405 & 0.0585 & 0.0694 & 0.0591 & 0.0662 \\
\hline
\end{tabular}

layer decreases from $-0.6636 \mathrm{~mm}$ to $-0.6226 \mathrm{~mm}$, indicating that the point has horizontal deformation in the opposite direction. After the load is added to $2.29 \mathrm{MPa}$, horizontal deformation in opposite directions appears on both sides of the main crack on the right. Through the observations above, it can be found that the main oblique crack on the left is mainly caused by the difference in vertical deformation, while the main oblique crack on the right is caused by the horizontal displacement in opposite directions.
During the whole loading process, the upper 5-6 layers of the wall basically maintain vertical deformation, while the mark points on the left side of the wall show visible horizontal deformation in addition to vertical displacement. Due to the uneven deformation of the wall, additional stress is generated in the upper part. When the stress exceeds the ultimate strength of the wall, oblique cracks characterized by shear failure appear. In the middle right part of the wall, the wall is damaged under compression during the entire loading process. In addition to vertical 


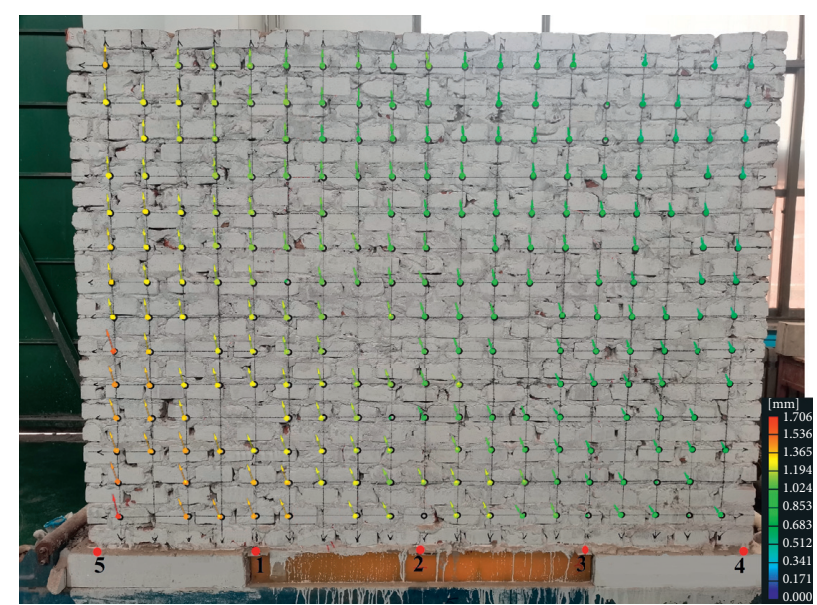

(a)

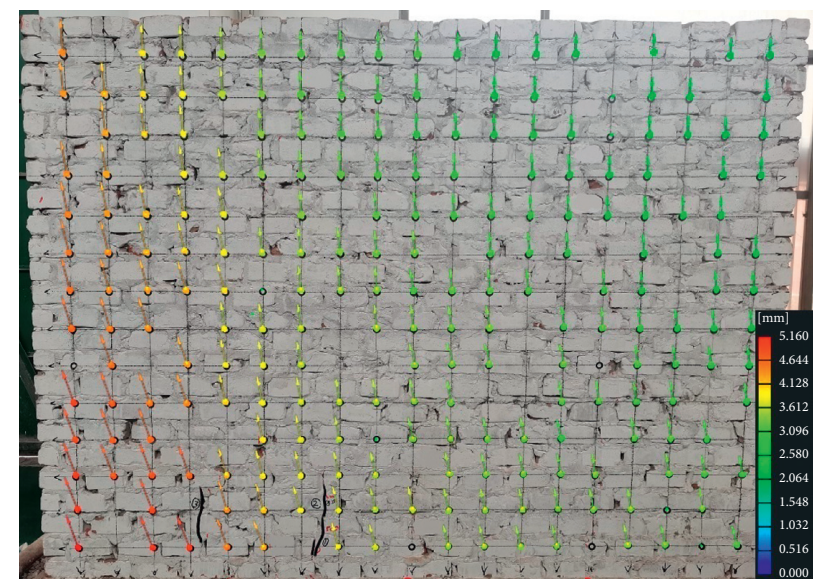

(c)

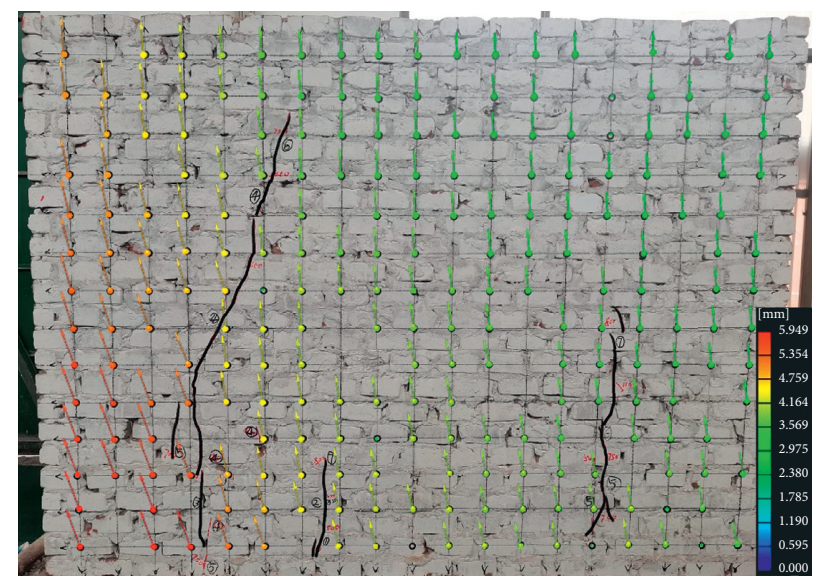

(e)

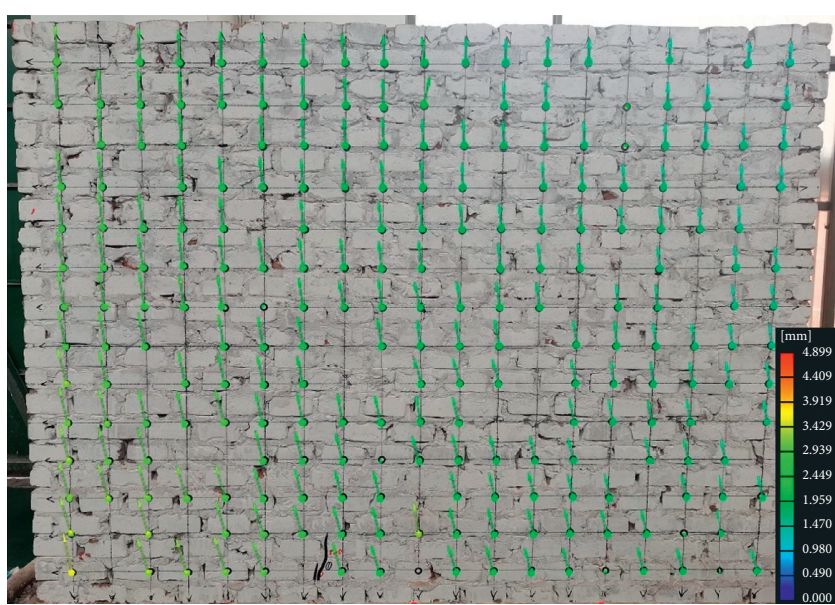

(b)

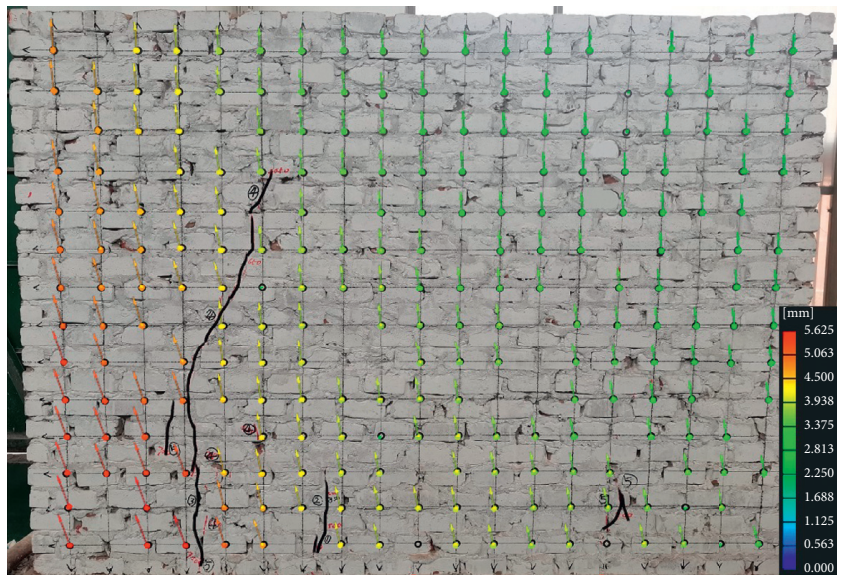

(d)

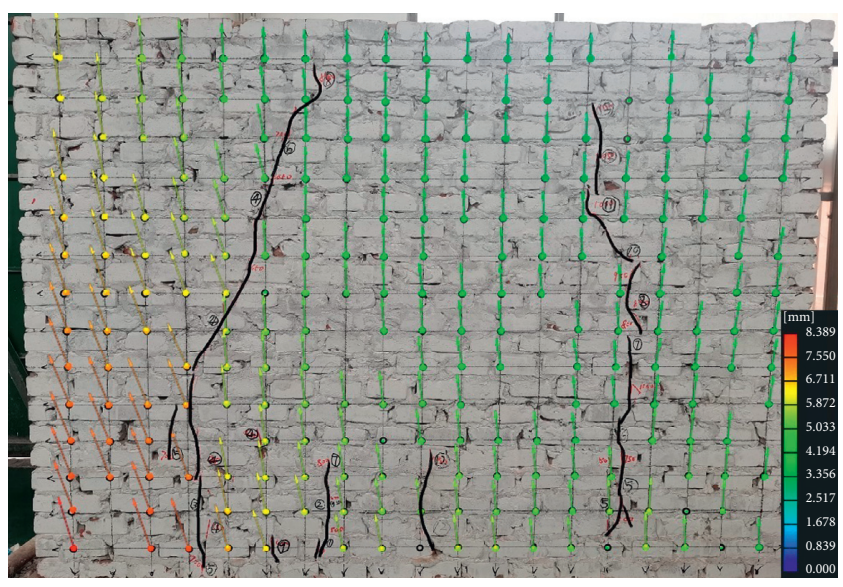

(f)

FIGURE 14: Noncoding point displacement nephogram under different pressures. (a) 0.2 MPa. (b) 1.04 MPa. (c) 1.25MPa. (d) 1.45MPa. (e) $1.87 \mathrm{MPa}$. (f) $2.29 \mathrm{MPa}$.

deformation, horizontal deformation due to the displacement in opposite directions is also detected at the monitoring points. When the ultimate strength of the wall is exceeded, cracks develop above the "soft-hard" junction of the wall, and they do not appear to be as oblique as those on the left. The reason for the slight difference between the two main cracks might be that, in the preparation of the wall, the gap width between the concrete and the polyurethane panels on both ends of the wall bottom is different, causing greater displacement of the left side of the wall. In short, the development of wall cracks can be explained by using this technique. 
TABle 3: Deformation of some noncoding point ID.

\begin{tabular}{|c|c|c|c|c|c|c|c|c|c|c|}
\hline \multirow{3}{*}{$\begin{array}{l}\text { Press } \\
\text { ID }\end{array}$} & \multicolumn{2}{|c|}{$1.04 \mathrm{MPa}$} & \multirow{2}{*}{\multicolumn{2}{|c|}{$1.25 \mathrm{MPa}$}} & \multirow{2}{*}{\multicolumn{2}{|c|}{$\begin{array}{c}1.45 \mathrm{MPa} \\
\text { Deformation }(\mathrm{mm})\end{array}$}} & \multirow{2}{*}{\multicolumn{2}{|c|}{$1.87 \mathrm{MPa}$}} & \multicolumn{2}{|c|}{$2.29 \mathrm{MPa}$} \\
\hline & & & & & & & & & & \\
\hline & Horizontal & Vertical & Horizontal & Vertical & Horizontal & Vertical & Horizontal & Vertical & Horizontal & Vertical \\
\hline 1076 & -0.0281 & 2.6762 & -0.0517 & 3.1419 & -0.1408 & 3.2492 & -0.1518 & 3.4454 & -0.244 & 3.8283 \\
\hline 1075 & 0.007 & 2.5665 & -0.0893 & 2.9583 & -0.1441 & 3.1009 & -0.1384 & 3.6739 & -0.247 & 4.1006 \\
\hline 1095 & -0.2195 & 2.649 & -0.1462 & 2.9288 & -0.1471 & 3.0214 & -0.1139 & 3.3627 & -0.1633 & 3.6821 \\
\hline 1070 & -0.0836 & 2.7373 & -0.1675 & 3.1947 & -0.2218 & 3.3438 & -0.3665 & 3.7604 & -0.5844 & 4.2397 \\
\hline 1067 & -0.0672 & 2.5951 & -0.1904 & 2.9661 & -0.2588 & 3.1496 & -0.259 & 3.4962 & -0.366 & 3.8953 \\
\hline 1228 & -0.0859 & 2.5321 & -0.2112 & 2.929 & -0.2109 & 3.0804 & -0.1296 & 3.4098 & -0.1531 & 3.8296 \\
\hline 1053 & -0.2245 & 2.8338 & -0.5765 & 3.4266 & -0.6678 & 3.632 & -0.9453 & 4.1874 & -1.3535 & 4.8099 \\
\hline 1054 & -0.2614 & 2.7068 & -0.5592 & 3.1624 & -0.609 & 3.3917 & -0.9529 & 3.8369 & -1.3398 & 4.3428 \\
\hline 1048 & -0.196 & 2.6152 & -0.2511 & 3.0423 & -0.2423 & 3.2126 & -0.1584 & 3.6389 & -0.215 & 4.0814 \\
\hline 1156 & -0.954 & 3.2905 & -1.7165 & 4.1024 & -1.796 & 4.4203 & -2.4244 & 5.3993 & -2.9328 & 6.2953 \\
\hline 1110 & -0.9533 & 3.1722 & -1.6808 & 3.9809 & -1.7692 & 4.3416 & -2.3668 & 5.3197 & -2.9072 & 6.2368 \\
\hline 1115 & -0.9728 & 3.0198 & -1.2267 & 3.597 & -1.0936 & 3.8736 & -1.3281 & 4.5996 & -1.5348 & 5.1991 \\
\hline 1105 & -1.1513 & 3.3896 & -1.8184 & 4.1974 & -1.8516 & 4.5494 & -2.4156 & 5.6199 & -2.8321 & 6.5758 \\
\hline 1109 & -1.128 & 3.3405 & -1.7976 & 4.1747 & -1.8286 & 4.566 & -2.3718 & 5.6422 & -2.7919 & 6.6374 \\
\hline 1112 & -1.0786 & 3.2105 & -1.5474 & 3.8713 & -1.4269 & 4.2542 & -1.8855 & 5.0833 & -2.2099 & 5.8 \\
\hline 1066 & -0.0905 & 2.0994 & -0.1117 & 2.5195 & -0.1126 & 2.6865 & -0.1433 & 3.0055 & -0.039 & 3.3003 \\
\hline 1238 & -0.0735 & 2.06 & -0.146 & 2.4742 & -0.1226 & 2.589 & -0.2227 & 3.0204 & 0.0224 & 3.4108 \\
\hline 1138 & -0.1173 & 2.1287 & -0.124 & 2.598 & -0.1257 & 2.7111 & -0.181 & 3.1016 & -0.135 & 3.4368 \\
\hline 1094 & -0.1798 & 2.1289 & -0.2235 & 2.5359 & -0.1778 & 2.6673 & -0.2711 & 3.0384 & -0.1814 & 3.3488 \\
\hline 1236 & -0.1723 & 2.0558 & -0.2759 & 2.4856 & -0.2223 & 2.6319 & -0.2494 & 3.0675 & -0.0071 & 3.4582 \\
\hline 1170 & -0.2571 & 2.2119 & -0.2999 & 2.6199 & -0.3397 & 2.768 & -0.3792 & 3.1998 & -0.4113 & 3.5832 \\
\hline 1046 & -0.3311 & 2.2044 & -0.3294 & 2.5566 & -0.3234 & 2.7738 & -0.4049 & 3.2021 & -0.426 & 3.5923 \\
\hline 1150 & -0.3197 & 2.1483 & -0.3235 & 2.4913 & -0.3908 & 2.7609 & -0.3217 & 3.1095 & 0.0023 & 3.6286 \\
\hline 1036 & -0.3559 & 2.2349 & -0.376 & 2.5805 & -0.448 & 2.8805 & -0.4551 & 3.2269 & -0.5161 & 3.6377 \\
\hline 1037 & -0.388 & 2.1457 & -0.3945 & 2.4858 & -0.4133 & 2.6864 & -0.2832 & 3.1004 & 0.121 & 3.7228 \\
\hline 1019 & -0.4973 & 2.3475 & -0.569 & 2.6901 & -0.6131 & 2.9639 & -0.628 & 3.2499 & -0.7391 & 3.7683 \\
\hline 1020 & -0.3958 & 2.3256 & -0.4272 & 2.6747 & -0.5604 & 2.8776 & -0.5069 & 3.2204 & -0.6801 & 3.6962 \\
\hline 1021 & -0.4802 & 2.15 & -0.5105 & 2.5446 & -0.5385 & 2.7697 & -0.3618 & 3.1922 & 0.0879 & 3.8545 \\
\hline 1142 & -0.6436 & 2.2324 & -0.7001 & 2.729 & -0.7791 & 2.8725 & -0.8343 & 3.1934 & -0.9207 & 3.7064 \\
\hline 1146 & -0.5968 & 2.1386 & -0.6548 & 2.6655 & -0.7391 & 2.7352 & -0.7995 & 3.1146 & -0.8217 & 3.616 \\
\hline 1005 & -0.5828 & 2.1788 & -0.6636 & 2.6468 & -0.6226 & 2.7943 & -0.5057 & 3.2692 & -0.0329 & 3.9108 \\
\hline 1140 & -0.7603 & 2.3223 & -0.8573 & 2.7565 & -0.8495 & 3.0751 & -1.013 & 3.5135 & -0.9777 & 4.0493 \\
\hline 1147 & -0.8044 & 2.2806 & -0.8835 & 2.7607 & -0.9066 & 3.0765 & -0.9115 & 3.6241 & -0.861 & 4.3958 \\
\hline 1220 & -0.7642 & 2.2829 & -0.8529 & 2.7471 & -0.8808 & 2.9737 & -0.7989 & 3.5674 & -0.3949 & 4.5969 \\
\hline
\end{tabular}

\section{Conclusions}

In this paper, the crack development of a full-scale wall caused by differential settlement of the foundation is studied by using $\mathrm{AE}$ and digital image processing technology, and the following conclusions are drawn:

(1) In the case of differential settlement with small settlement on both sides and large settlement in the middle, two main oblique cracks-one on the left and the other on the right-develop from the junction of the concrete block and polyurethane panels, extending from bottom to top.

(2) During the loading process, damage of the wall is aggravated due to differential settlement, and thus, the cumulative ringing count and energy count show a steep rise in different stages. As the load increases and AE events are activated, the cumulative ringing count and cumulative energy curves have an obvious turning point, and the slope of the curves is substantially higher than that in the early stage of loading. In the later stage of loading, due to frequent $\mathrm{AE}$ activities, the ringing counts are relatively high, and the slopes of the curves reach their maximum.

(3) Digital close-range industrial photogrammetry can be used to effectively detect the displacement and deformation of the feature points on the wall. According to the deformation of the feature points, the main oblique crack on the left is mainly caused by the uneven deformation of the wall bottom, which leads to the vertical settlement difference of the wall, while the main oblique crack on the right is caused by the displacement of the wall on both sides of the crack in opposite directions.

\section{Data Availability}

The data generated and analyzed in this manuscript are available from the corresponding author upon reasonable request. 


\section{Conflicts of Interest}

The authors declare that there are no conflicts of interest regarding the publication of this paper.

\section{Acknowledgments}

This research was supported by the Natural Science Foundation of China under Grant no. 51678475 and Natural Science Basic Research Program of Shaanxi under Grant no. 2018JZ5002. The financial support is gratefully acknowledged.

\section{References}

[1] T. Janda, M. Šejnoha, and J. Šejnoha, "Modeling of soil structure interaction during tunnel excavation: an engineering approach," Advances in Engineering Software, vol. 6263, pp. 51-60, 2013.

[2] A. Spada, "The effect of vertical ground movement on masonry walls simulated through an elastic-plastic interphase meso-model: a case study," Archive of Applied Mechanics, vol. 89, no. 8, pp. 1655-1676, 2019.

[3] G. Giardina, A. V. Van de Graaf, M. A. N. Hendriks, J. G. Rots, and A. Marini, "Numerical analysis of a masonry façade subject to tunnelling-induced settlements," Engineering Structures, vol. 54, pp. 234-247, 2013.

[4] L. Bejarano-Urrego, E. Verstrynge, G. Giardina, and K. Van Balen, "Crack growth in masonry: numerical analysis and sensitivity study for discrete and smeared crack modelling," Engineering Structures, vol. 165, pp. 471-485, 2018.

[5] L. Bejarano-Urrego, E. Verstrynge, A. Drougkas et al., "Numerical analysis of settlement-induced damage to a masonry church nave wall," RILEM Bookseries, vol. 18, pp. 853-861, 2019.

[6] A. Drougkas, E. Verstrynge, P. Szekér et al., "Numerical modeling of a church nave wall subjected to differential settlements: soil-structure interaction, time-dependence and sensitivity analysis," International Journal of Architectural Heritage, vol. 14, no. 8, pp. 1221-1238, 2020.

[7] C. Alessandri, M. Garutti, V. Mallardo, and G. Milani, "Crack patterns induced by foundation settlements: integrated analysis on a renaissance masonry palace in Italy," International Journal of Architectural Heritage, vol. 9, no. 2, pp. 111-129, 2015.

[8] M. Son and E. J. Cording, "Estimation of building damage due to excavation-induced ground movements," Journal of Geotechnical and Geoenvironmental Engineering, vol. 131, no. 2, pp. 162-177, 2005.

[9] M. Son and E. J. Cording, "Evaluation of building stiffness for building response analysis to excavation-induced ground movements," Journal of Geotechnical and Geoenvironmental Engineering, vol. 133, no. 8, pp. 995-1002, 2007.

[10] D. F. Laefer, L. T. Hong, A. Erkal, J. H. Long, and E. J. Cording, "Manufacturing, assembly, and testing of scaled, historic masonry for one-gravity, pseudo-static, soil-structure experiments," Construction and Building Materials, vol. 25, no. 12, pp. 4362-4373, 2011.

[11] H. L. Nghiem, M. A. Heib, and F. Emeriault, "Physical model for damage prediction in structures due to underground excavations," in Proceedings of the International Conference on Geotechnical Engineering, pp. 155-164, Geo-shanghai, Shanghai, China, May 2014.
[12] S. Ritter, G. Giardina, M. J. DeJong, and R. J. Mair, "Centrifuge modelling of building response to tunnel excavation," International Journal of Physical Modelling in Geotechnics, vol. 18, no. 3, pp. 146-161, 2018.

[13] G. Giardina, A. Marini, M. A. N. Hendriks, J. G. Rots, F. Rizzardini, and E. Giuriani, "Experimental analysis of a masonry façade subject to tunnelling-induced settlement," Engineering Structures, vol. 45, pp. 421-434, 2012.

[14] G. Giardina, M. A. N. Hendriks, and J. G. Rots, "Sensitivity study on tunnelling induced damage to a masonry façade," Engineering Structures, vol. 89, pp. 111-129, 2015.

[15] G. Giardina, A. Marini, P. Riva, and E. Giuriani, "Analysis of a scaled stone masonry facade subjected to differential settlements," International Journal of Architectural Heritage, vol. 14, no. 10, p. 1502, 2019.

[16] F. Portioli and L. Cascini, "Assessment of masonry structures subjected to foundation settlements using rigid block limit analysis," Engineering Structures, vol. 113, pp. 347-361, 2016.

[17] F. Portioli and L. Cascini, "Large displacement analysis of dryjointed masonry structures subjected to settlements using rigid block modelling," Engineering Structures, vol. 148, pp. 485-496, 2017.

[18] B. Torres, E. Bertolesi, J. J. Moragues, P. A. Calderón, and J. M. Adam, "Experimental investigation of a full-scale timbrel masonry cross vault subjected to vertical settlement," Construction and Building Materials, vol. 221, pp. 421-432, 2019.

[19] E. Verstrynge, K. De Wilder, A. Drougkas, E. Voet, K. Van Balen, and M. Wevers, "Crack monitoring in historical masonry with distributed strain and acoustic emission sensing techniques," Construction and Building Materials, vol. 162, pp. 898-907, 2018.

[20] Z. Orbán and M. Gutermann, "Assessment of masonry arch railway bridges using non-destructive in-situ testing methods," Engineering Structures, vol. 31, no. 10, pp. 2287-2298, 2009.

[21] A. Carpinteri and G. Lacidogna, "Damage monitoring of an historical masonry building by the acoustic emission technique," Materials and Structures, vol. 39, no. 2, pp. 161-167, 2006.

[22] A. Carpinteri, G. Lacidogna, F. Accornero, A. C. Mpalaskas, T. E. Matikas, and D. G. Aggelis, "Influence of damage in the acoustic emission parameters," Cement and Concrete Composites, vol. 44, pp. 9-16, 2013.

[23] E. Njuhovic, M. Bräu, F. Wolff-Fabris, K. Starzynski, and V. Altstädt, "Identification of interface failure mechanisms of metallized glass fibre reinforced composites using acoustic emission analysis," Composites Part B: Engineering, vol. 66, pp. 443-452, 2014.

[24] S. De Santis and A. K. Tomor, "Laboratory and field studies on the use of acoustic emission for masonry bridges," NDT \& $E$ International, vol. 55, pp. 64-74, 2013.

[25] P. Antonaci, P. Bocca, and D. Masera, "Fatigue crack propagation monitoring by Acoustic Emission signal analysis," Engineering Fracture Mechanics, vol. 81, pp. 26-32, 2012.

[26] M. Uranjek and V. Bokan-Bosiljkov, "Influence of freeze-thaw cycles on mechanical properties of historical brick masonry," Construction and Building Materials, vol. 84, pp. 416-428, 2015.

[27] Y. Wu, S. Li, and D. Wang, "Characteristic analysis of acoustic emission signals of masonry specimens under uniaxial compression test," Construction and Building Materials, vol. 196, pp. 637-648, 2019.

[28] Y. Wu, S. Li, D. Wang, and G. Zhao, "Damage monitoring of masonry structure under in-situ uniaxial compression test 
using acoustic emission parameters," Construction and Building Materials, vol. 215, pp. 812-822, 2019.

[29] A. Grazzini, F. Accornero, G. Lacidogna, and S. Valente, "Acoustic emission and numerical analysis of the delamination process in repair plasters applied to historical walls," Construction and Building Materials, vol. 236, 2020.

[30] China Building Industry Press, Chinese Standard GB/T 25422012, Test Methods for Wall Bricks. GB/T 2542-2012, China Building Industry Press, Beijing, China, 2012, in Chinese.

[31] China Building Industry Press, Chinese Trade Standard JGJ/ T70-2009, Standard for Test Method of Performance on Building mortar JGJ/T70-2009, China Building Industry Press, Beijing, China, 2009, in Chinese.

[32] China Building Industry Press, Chinese Standard GB/T501292011, Standard for Test Method of Basic Mechanics Propeorties of Masonry. GB/T50129-2011, China Building Industry Press, Beijing, China, 2011, in Chinese.

[33] Y. Xu, K. Wu, L. Li, D. Zhou, and Z. Hu, "Ground cracks development and characteristics of strata movement under fast excavation: a case study at Bulianta coal mine, China," Bulletin of Engineering Geology and the Environment, vol. 78, no. 1, pp. 325-340, 2019.

[34] D.-H. Zhang, L. Jin, C. Guo, J.-W. Liu, X.-Q. Zhang, and Z.-X. Chen, "Exploitation of photogrammetry measurement system," Optical Engineering, vol. 49, no. 3, pp. 263-276, 2010.

[35] K. Wu, G.-L. Cheng, and D.-W. Zhou, "Experimental research on dynamic movement in strata overlying coal mines using similar material modeling," Arabian Journal of Geosciences, vol. 8, no. 9, pp. 6521-6534, 2015. 